\title{
Influence of substrate temperature and gas pressure on aluminum oxynitride coatings obtained by pulsed laser deposition
}

\author{
JoAnna PiWOWARCZYK*, Roman JĘDRZEJEwski, JolANTA BARANOWSKa \\ Institute of Materials Science and Engineering, West Pomeranian University of Technology, \\ al. Piastów 19, 70-310 Szczecin, Poland
}

\begin{abstract}
The paper presents results of the investigation on the influence of deposition parameters, such as substrate temperature, total gas pressure and reactive gas composition on the structure, chemical composition and mechanical properties of aluminum oxynitride coatings obtained by pulsed laser deposition (PLD) method. Selection of process parameter ranges, which could be promising for aluminum oxynitride (ALON) coatings deposition, was the main objective of the work. Two series of experiments were carried out with varied pressure and temperature. It was found that from the chemical composition viewpoint, the most promising are atmospheres containing $20 \%$ to $40 \%$ oxygen. The nitrogen to oxygen ratios in the coatings can be controlled by increasing the total pressure or substrate temperature. However, increasing the pressure has a negative effect on the $\mathrm{O}+\mathrm{N}: \mathrm{Al}$ ratio, mechanical properties and quality of the coatings. The influence of temperature is much less drastic and more controllable. Increasing the deposition temperature is much more beneficial since it improves the mechanical properties and can compensate to some extent the negative effect of the total pressure. From the coating quality viewpoint, it is possible to establish an optimum temperature range for which the coatings are characterized by a compact structure and a limited number of droplets.
\end{abstract}

Keywords: aluminum oxynitride coatings; pulsed laser deposition; temperature and pressure influence; chemical composition

(C) Wroclaw University of Science and Technology.

\section{Introduction}

Aluminum oxynitride (ALON) is a polycrystalline ceramic material with a general chemical composition: $\mathrm{Al}_{(64+\mathrm{x}) / 3} \mathrm{O}_{32-\mathrm{x}} \mathrm{N}_{\mathrm{x}}$, where $0 \leqslant \mathrm{x} \leqslant 8[1,2]$. ALON ceramics is used for infrared and visible windows, abrasives and armor materials, optical coatings [3] and optoelectronic applications [4]. This is because of excellent properties, such as high strength and high hardness [5-7], transparency for wavelength from ultraviolet (UV) to mid-infrared (MIDIR) $[2,7,8]$ and high temperature resistance (melting temperature of $2150{ }^{\circ} \mathrm{C}$ ) and corrosion resistance [9].

There is an extensive research literature available on the production of ALON powders and its subsequent processing [9-12]. However, these techniques require the use of high

*E-mail: Joanna.Piwowarczyk@zut.edu.pl temperatures (above $1600{ }^{\circ} \mathrm{C}$ ), long production times and chemical additives. This leads to high production costs for ALON and limits its commercial applications. This means that deposition methods which do not require the use of ALON powders would be highly beneficial. There are only few publications describing the deposition of aluminum oxynitride layers by means of physical methods: radio frequency magnetron sputtering [10] and ion-beam-assisted pulsed laser deposition [13], but they suggest that high energy beams seem to be a promising tool for obtaining high temperature ceramic coatings. Therefore, in our previous studies [14, 15] we made an attempt to obtain an AlON film using pulsed laser deposition (PLD) and pulsed electron deposition (PED) methods. In our experiments, AlN ceramic was used as the target material and oxygen as the background gas. This choice was made due to the fact that high temperature and the presence of oxygen led to the oxidation of $\mathrm{AlN}$ and its conversion to $\mathrm{Al}_{2} \mathrm{O}_{3}[13,16]$. 
Furthermore, the addition of $\mathrm{Al}_{2} \mathrm{O}_{3}$ to AlN leads to AlON formation [7]. Our preliminary investigations demonstrated the presence of oxynitrides in the coatings obtained by PED and PLD methods. Technical details of the experiments were presented in our previous works $[14,15]$.

Our current work focuses on the selection of process parameter ranges which could be promising for ALON coatings deposition as there is a lack of literature concerning this topic. Previous investigations were focused on the influence of different oxygen-to-nitrogen ratios in reactive atmosphere on the structure and properties of the coatings [17]. These results showed that it was possible to obtain coatings composed of oxynitrides with different stoichiometry and that the most beneficial oxygen-to-nitrogen ratio was 4:6. However, the amount of oxygen and nitrogen atoms in the coatings in relation to the aluminum concentration was unsatisfactory. The current work is a continuation of the previous research [17] and aims to establish a range of other parameters of the deposition process, such as temperature and pressure, which enable aluminum oxynitride coatings to be produced with ALON stoichiometry.

\section{Experimental}

The coatings were deposited by means of a PLD system (NEOCERA, Inc., USA) and the material ablation was achieved using an excimer laser (He/Ne; $\mathrm{KrF}, \lambda=248 \mathrm{~nm}$ ). Details of the technique have been published in the literature [14].

The coatings were grown on monocrystalline $\mathrm{Si}$ ( $\left.\begin{array}{lll}1 & 0 & 0\end{array}\right)$ substrates of dimensions $10 \mathrm{~mm} \times 10 \mathrm{~mm}$. Prior to the deposition process, the substrates were ultrasonically cleaned in an acetone bath, rinsed in acetone and isopropyl alcohol and dried in an air flow.

A $99 \%$ purity aluminum nitride (AlN) bulk disk was used as a target. The target was rotated during the deposition process in order to avoid local overheating and transition to the liquid phase. The distance between the target and the substrate was set at $70 \mathrm{~mm}$.

The film deposition took place at an oxygen-tonitrogen ratio of 4:6 in the background gas which was selected based on the previous studies [17]. Two series of experiments were carried out: one with pressure varied from $1.0 \mathrm{~Pa}$ to $25 \mathrm{~Pa}$ at room temperature (RT) and the other one with temperature varied from $20{ }^{\circ} \mathrm{C}$ to $800{ }^{\circ} \mathrm{C}$ at $1.2 \mathrm{~Pa}$. Moreover, an additional process was carried out at $800{ }^{\circ} \mathrm{C}$ and $5 \mathrm{~Pa}$ in order to investigate how both parameters influence each other. The deposition time corresponded to 30000 pulses of laser with a repetition rate of $10 \mathrm{~Hz}$, corresponding to $50 \mathrm{~min}$.

The film thickness and roughness $(\mathrm{Ra})$ were determined by means of a profilometer (Dektak 6M, Veeco). The thickness was estimated by measuring the step between the coated surface and an uncoated part of the substrate which remained uncovered during the deposition. The results were used to calculate the deposition rate.

The chemical composition was evaluated using X-ray microanalysis (EDS and WDS, Noran 7 system of Thermo Scientific) installed on a scanning electron microscope (FE-SEM SU-70, Hitachi). The latter was also used for surface examination. During the analysis of the results, it was found that evaluating the coating composition based on WDS analysis gives underestimated values of oxygen and nitrogen concentrations in relation to the quantity of aluminum due to the small thickness of the coating in comparison to the analyzed volume of the material. Therefore, a modified procedure was applied to estimate the coating composition based on the results obtained by both WDS and EDS methods. The concentration of nitrogen and oxygen was measured using the WDS method and the oxygen concentration, and aluminum to oxygen ratio were determined using the EDS method. Based on these data, the concentration of the elements was determined. The molecular structure was then recalculated for 23 aluminum atoms which are typical of the most stable and stoichiometric ALON phase represented by $\mathrm{Al}_{23} \mathrm{O}_{27} \mathrm{~N}_{5}$ (when $\mathrm{x}=5$ ) [5], hereinafter referred to as ALON 5 in the text.

The surface topography was examined using an atomic force microscope (AFM; Veeco NanoScope IVa); $20 \mu \mathrm{m} \times 20 \mu \mathrm{m}$ images were obtained in the contact mode. In addition, the average $\mathrm{Ra}$ value 
was determined for the area between the droplets on $5 \mu \mathrm{m}^{2}$ areas.

Nanoindentation (NanoIndenter XP, Agilent) was used for hardness and Young's modulus measurements.

\section{Results}

\subsection{Influence of the substrate tempera- ture on the topography, thickness and me- chanical properties of the coatings}

AFM $20 \mu \mathrm{m} \times 20 \mu \mathrm{m}$ images of the film surface topography are presented in Fig. 1. It can be noticed that the surface topography depends strongly on the substrate temperature. In general, the coating surface is smooth, however, a different number of droplets is observed depending on the substrate temperature. The coatings obtained at room temperature and at $600{ }^{\circ} \mathrm{C}$ and $800{ }^{\circ} \mathrm{C}$ (Fig. 1a, Fig. 1d, Fig. 1e, respectively) show the highest number of droplets. The coatings obtained at $200{ }^{\circ} \mathrm{C}$ and $400{ }^{\circ} \mathrm{C}$ demonstrate the best surface quality with almost no droplets being visible in these cases.

The good quality of the samples obtained at $200{ }^{\circ} \mathrm{C}$ and $400{ }^{\circ} \mathrm{C}$ has also been confirmed by the results of the roughness measurements. Fig. 2 presents the results of roughness measurements carried out using surface profilometry and AFM methods. The former measurements included the droplets, whilst the AFM measurements were performed between the droplets. It can be seen that the presence of droplets significantly increases the roughness of the coatings obtained at $600{ }^{\circ} \mathrm{C}$ and $800{ }^{\circ} \mathrm{C}$ which coincides well with the surface images. When analyzing the roughness of the coatings measured between the droplets, it can be observed that the coatings obtained at $200{ }^{\circ} \mathrm{C}$ and $600{ }^{\circ} \mathrm{C}$ are the smoothest having an Ra parameter of $0.2 \mathrm{~nm}$ to $0.3 \mathrm{~nm}$. The roughness of the coatings obtained at RT and at $800{ }^{\circ} \mathrm{C}$ is 10 to 20 times higher. These observations suggest that there could be an optimum range of substrate temperature to obtain the best surface quality. This is in agreement with the results of other studies [18-20]. For example, Liu et al. [21] observed similar phenomena for $\mathrm{ZnO}$ coatings obtained by the PLD method. This was explained on the basis of enhanced atomic mobility and diffusion on the surface of the film at higher temperature. As a result, smoother coatings can be obtained. However, when the substrate temperature is too high, the adatoms with too high kinetic energy collide quickly with each other and are reevaporated. As a result, a mass of dislocations in the thin film induces higher roughness. Taking into account that the melting temperature of ALON is of the same order as that of $\mathrm{ZnO}$, a similar phenomenon may also be expected for ALON.

The results of thickness measurements showed that the deposition temperature had no influence on the film thickness (Fig. 3). All coatings demonstrate a similar thickness of about $300 \mathrm{~nm}$, although the layer obtained at $400{ }^{\circ} \mathrm{C}$ is slightly thicker. The calculated value of the deposition rate is about $0.01 \mathrm{~nm}$ per pulse.

The influence of temperature on hardness and Young's modulus was also investigated (Fig. 4 and Fig. 5). The results showed that increasing the substrate temperature enhanced the mechanical properties of the coatings. The hardness increased from about $12 \mathrm{GPa}$ to about $16.5 \mathrm{GPa}$ (Fig. 4), when temperature raised from room temperature to $800{ }^{\circ} \mathrm{C}$, respectively. The values of Young's modulus increased from $179 \mathrm{GPa}$ to $197 \mathrm{GPa}$ (Fig. 5) for the same temperatures range. The highest growth has been noticed between $600{ }^{\circ} \mathrm{C}$ and $800{ }^{\circ} \mathrm{C}$.

\subsection{Total pressure influence on the topog- raphy, thickness and mechanical properties of the coatings}

Fig. 6 shows AFM $20 \mu \mathrm{m} \times 20 \mu \mathrm{m}$ images of the surface topographies of the coatings obtained at various pressures. The adhesion of the coating obtained at the highest pressure was very low; AFM imaging was in this case not possible because the particles became detached and swept by the tip movement (Fig. 6d). For these coatings, the surface topography is presented in the SEM image (Fig. 6e). All the films seem to exhibit good smoothness, and when the pressure increased, the number of droplets decreased. However, the roughness measurements (Fig. 7) indicated that an increase in gas pressure caused 


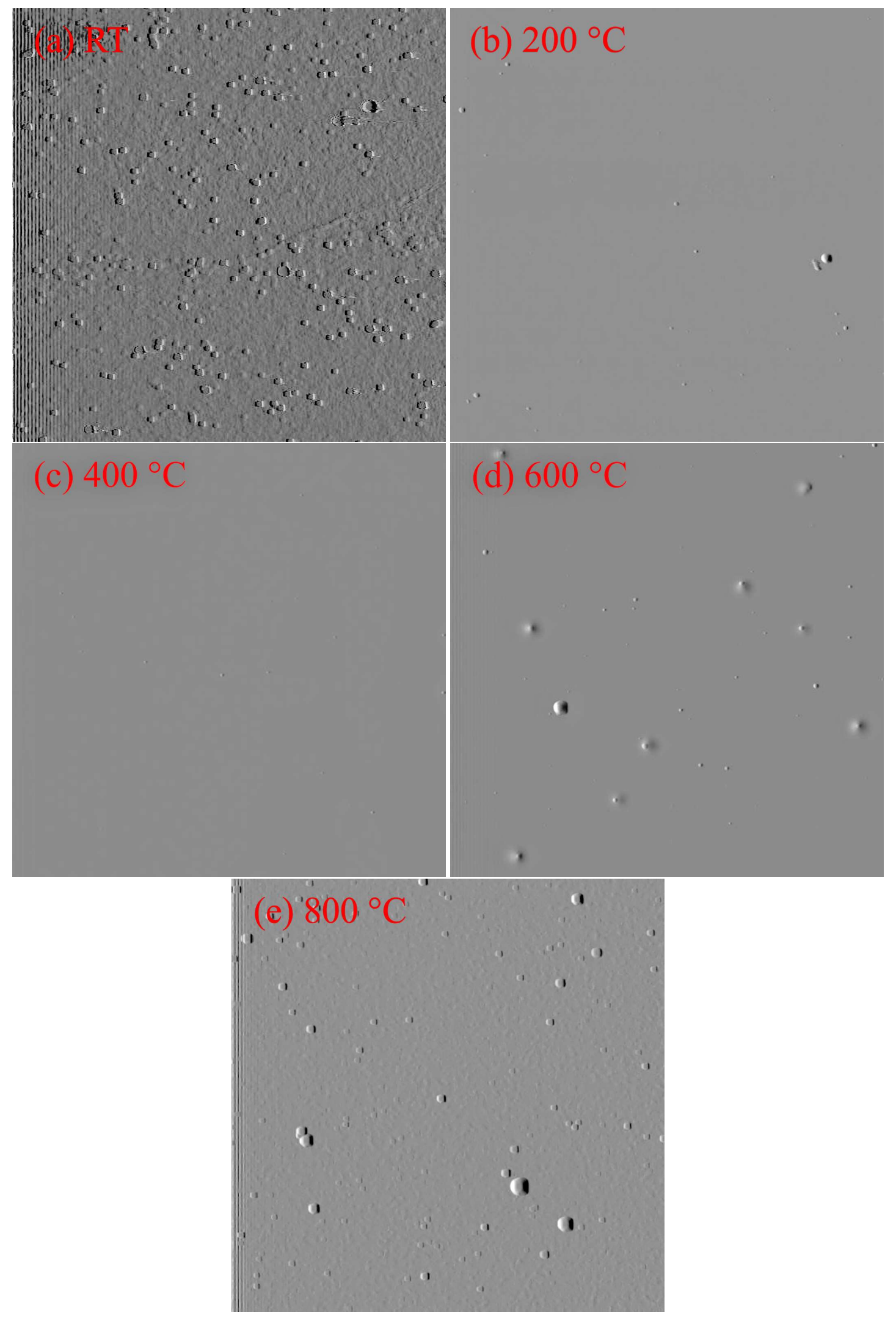

Fig. 1. AFM images of surface topography $(20 \mu \mathrm{m} \times 20 \mu \mathrm{m})$ of coatings obtained at different substrate temperatures. 


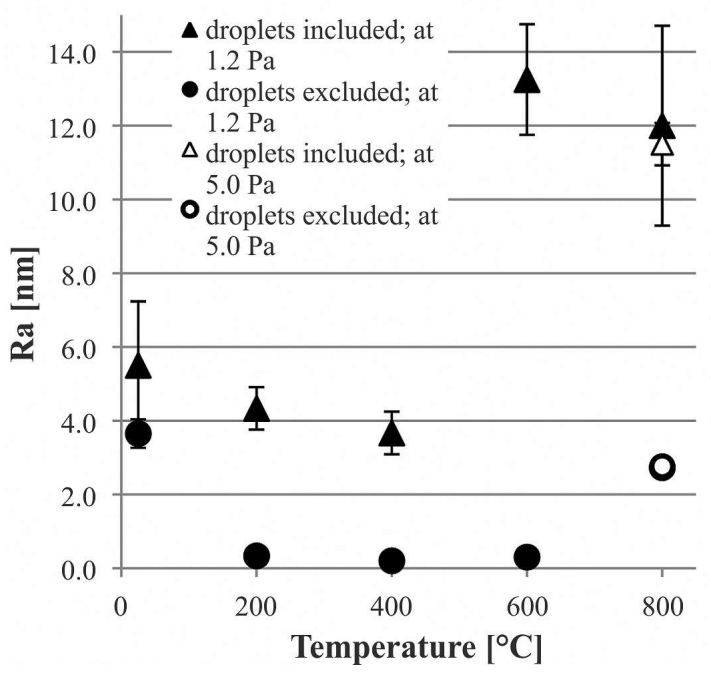

Fig. 2. Roughness of coatings obtained at different substrate temperatures.

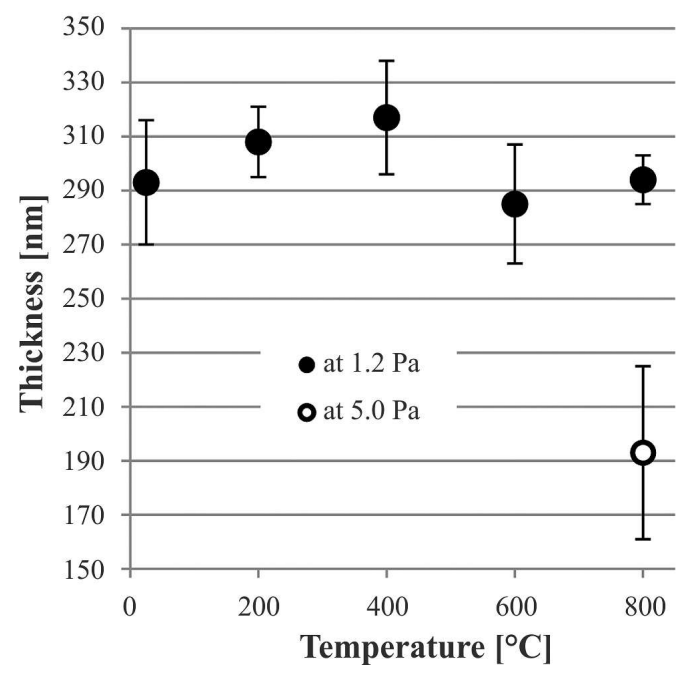

Fig. 3. Thickness of coatings obtained at different substrate temperatures.

a significant increase in roughness: from $4.5 \mathrm{~nm}$ to $11.0 \mathrm{~nm}$ determined with droplets, and from $0.5 \mathrm{~nm}$ to $12.8 \mathrm{~nm}$ determined without droplets. The same relationship between roughness and gas pressure has been mentioned in many publications, where ceramic coatings were deposited by the PLD method [22-26]. It was explained by the relationship between the mobility of atoms and their kinetic energy [22, 23, 25, 27]. When the gas pressure is low, collisions between the atoms

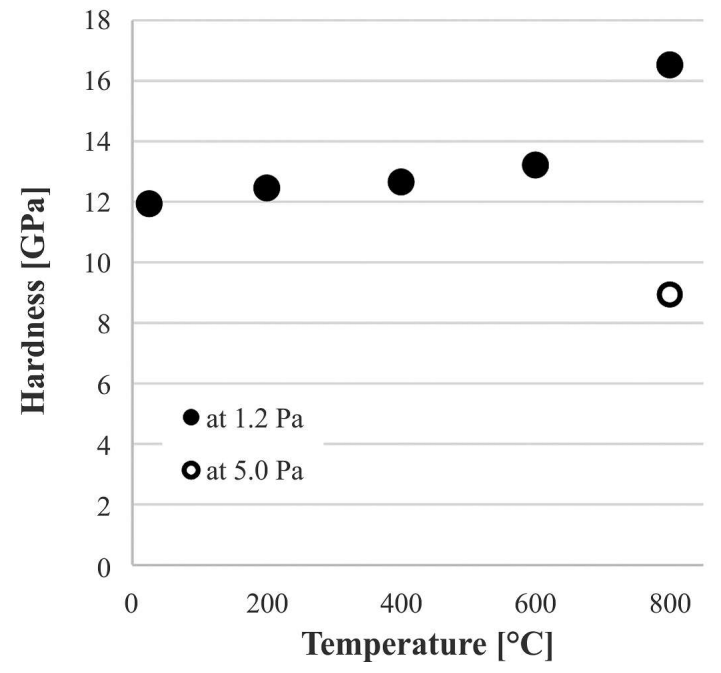

Fig. 4. Hardness of coatings obtained at different substrate temperatures.

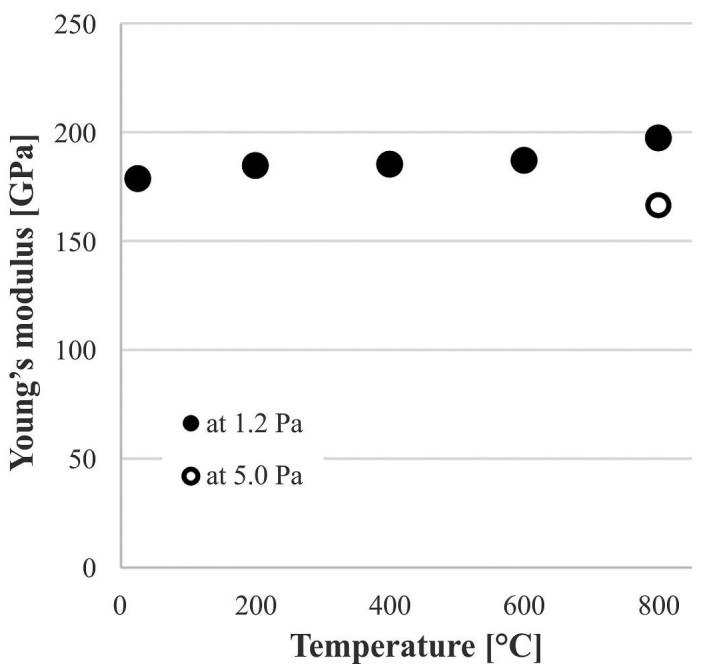

Fig. 5. Young's modulus of coatings obtained at different substrate temperatures.

in the plasma plume and the gas molecules are relatively infrequent, so that the atoms reaching the substrate surface have a relatively high kinetic energy. As a consequence, the re-evaporation of surface adatoms is induced which slows down the film growth and results in a smooth surface. When the gas pressure is high, collisions between molecules and atoms are more frequent. This results in a reduction of the energy of the atoms in the plasma plume. Hence, the capability 
of adatoms to move on the substrate surface decreases which leads to the formation of voids and a porous coating structure. As can be seen in Fig. 7, if the temperature increases, the smoothness of the coating is improved which corresponds well to the explanations presented above.

The results presented in Fig. 8 demonstrate that an increase in the gas pressure leads to a decrease of the coating thickness from $290 \mathrm{~nm}$ to $250 \mathrm{~nm}$. A similar tendency was shown by other authors $[23,25,28]$. It can be observed that the temperature increase reduces the thickness even more.

The results of the hardness and Young's modulus investigations are shown in Fig. 9 and Fig. 10, respectively. The samples obtained at $25 \mathrm{~Pa}$ were too thin and too uneven to be measured. The findings shown in Fig. 9 indicate that the hardness drastically diminished from $12 \mathrm{GPa}$ to about $1 \mathrm{GPa}$, when the pressure was increased from $1.0 \mathrm{~Pa}$ to $5 \mathrm{~Pa}$. A similar dependence can be observed for the Young's modulus (Fig. 10). The values obtained are in the range of $35 \mathrm{GPa}$ to $70 \mathrm{GPa}, 80 \mathrm{GPa}$ to $130 \mathrm{GPa}$, and $177 \mathrm{GPa}$ for pressures of $1 \mathrm{~Pa}, 2.5 \mathrm{~Pa}$ and $5 \mathrm{~Pa}$, respectively. It can also be observed that the mechanical properties can be improved by increasing the temperature (Fig. 9).

\subsection{Influence of the process parameters on the chemical composition of the coatings}

The chemical analysis results are presented in Fig. 10 and Fig. 11 for the experiments on the influence of temperature and pressure, respectively. It can be observed that as temperature increased, the nitrogen concentration in the coatings also increased. The oxygen concentration continuously decreased, as temperature increased up to $400{ }^{\circ} \mathrm{C}$, but above this temperature it remained almost stable. The oxygen + nitrogen to aluminum ratio $(\mathrm{O}+\mathrm{N}: \mathrm{Al})$ decreased slightly with temperature, approaching the desired value of 1.39 for ALON5 (Fig. 10b).

The influence of gas pressure on the chemical composition of the coatings is presented in Fig. 11. This chart includes the results obtained in previous work [17] for $0.5 \mathrm{~Pa}$ gas pressure which have been recalculated according to the methodology presented in the experimental part. An increase in pressure resulted in a significant increase in the oxygen content from 32.9 at.\% to 50.5 at.\%. However, an opposite effect was observed for the nitrogen concentration which dropped suddenly from 3.97 at.\% to 0.87 at.\%, just after the pressure increased to $1 \mathrm{~Pa}$. A further increase in pressure had no significant effect on the nitrogen concentration which remained almost stable. The resulting $\mathrm{O}+\mathrm{N}: \mathrm{Al}$ ratio increased significantly with the reactive gas pressure, moving further away from the desired value (Fig. 11b).

In order to compare the results obtained with those from previous work [17], the latter were recalculated using the same methodology as described in the experimental part. The new values are presented in Fig. 12. The same relationship as previously was observed, as regards the influence of the gas composition on the concentration of light elements in the coatings. An increase in oxygen content in the atmosphere led to an increase in the oxygen concentration and to a decrease in the nitrogen concentration in the coatings.

\section{Summary}

The experiments carried out enabled evaluation of the influence of deposition parameters, such as substrate temperature, total gas pressure and reactive gas composition on the structure, chemical composition and mechanical properties of aluminum oxynitride coatings obtained by the PLD method. From the chemical composition viewpoint of the coatings, the most promising are atmospheres containing between $20 \%$ and $40 \%$ oxygen. For this range, the oxygen concentration in the coatings obtained at $0.5 \mathrm{~Pa}$ varies between 22.6 at.\% and 32.9 at.\%, and the corresponding nitrogen concentration varies between 10.3 at.\% and 3.97 at.\%. These values are close to the concentrations expected for ALON5. Moreover, the $\mathrm{O}+\mathrm{N}$ :Al ratio only slightly exceeds the desired value of 1.39 . The nitrogen to oxygen ratio in the coatings can be controlled in two ways: increasing the total pressure or the substrate temperature. 


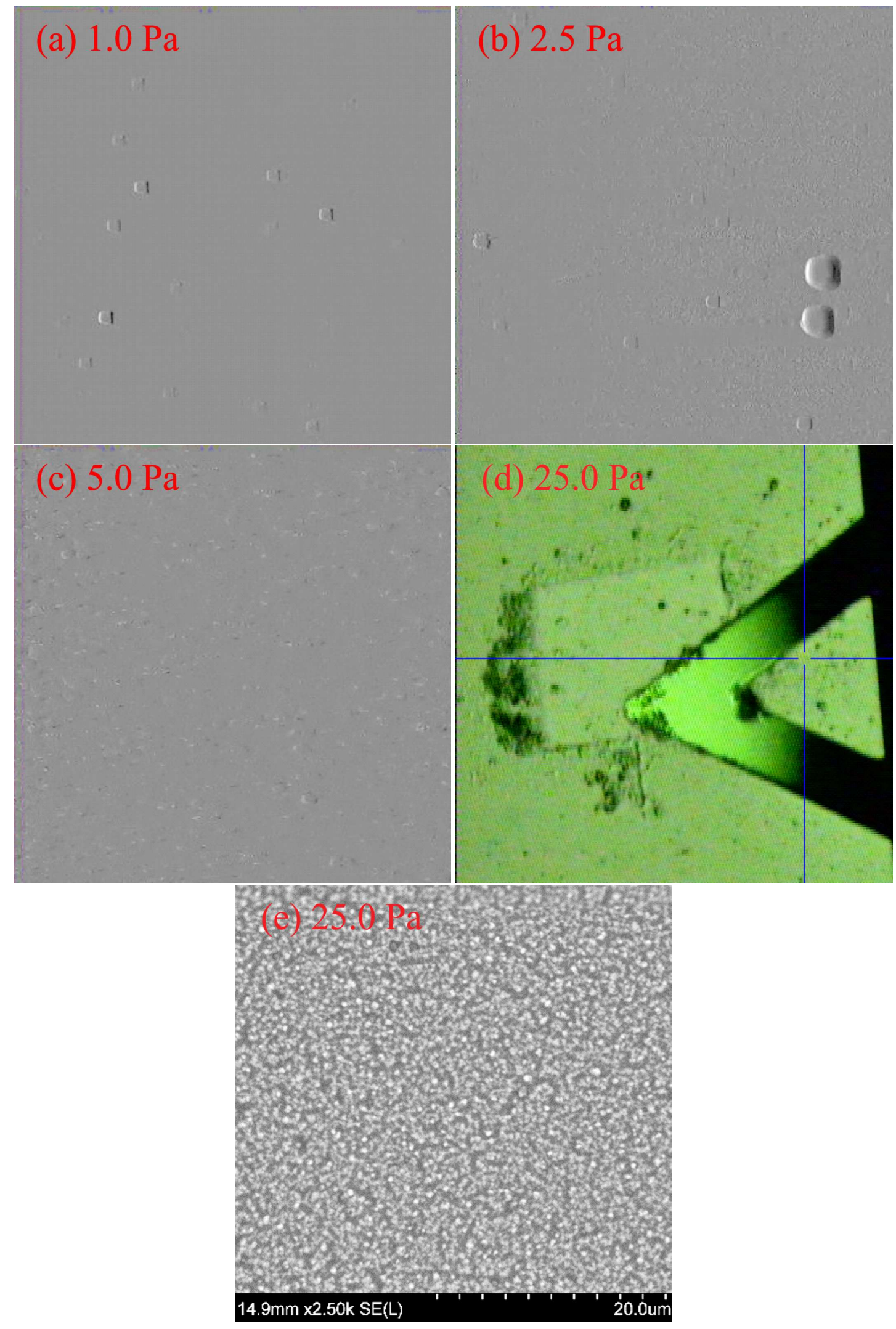

Fig. 6. Surface topography $(20 \mu \mathrm{m} \times 20 \mu \mathrm{m})$ of coatings obtained at various deposition pressures; (a) to (c) is AFM; (d) is optical microscopy, and (e) is SEM. 


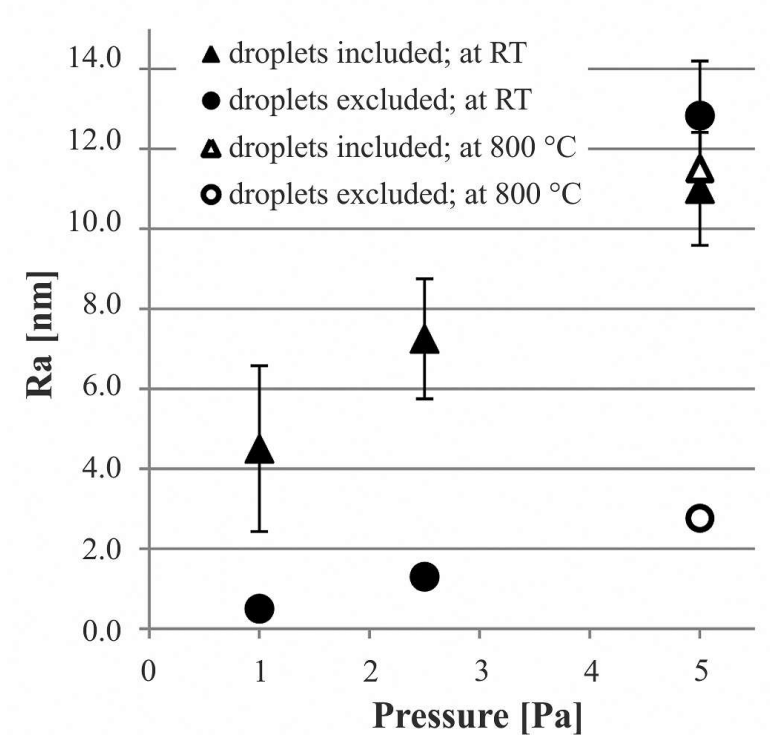

Fig. 7. Roughness of coatings obtained at various deposition pressures.

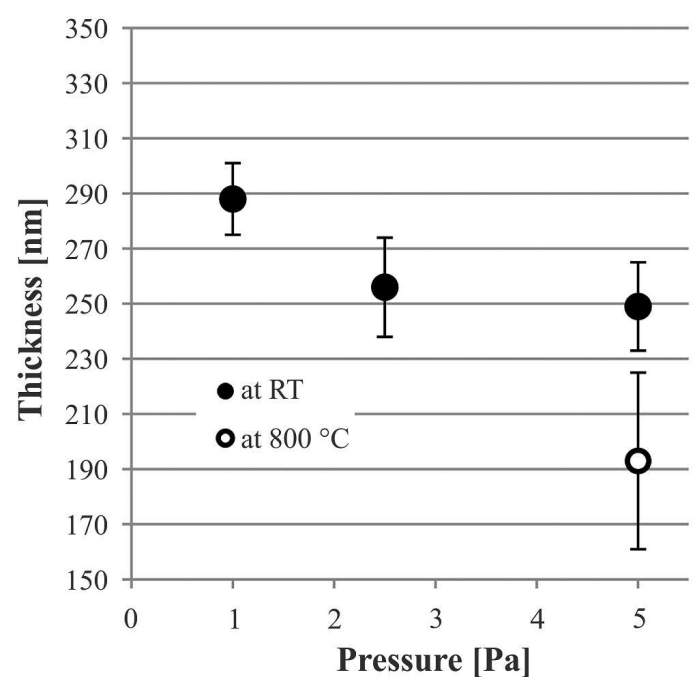

Fig. 8. Thickness of coating obtained at various deposition pressures.

Increasing the pressure has to be carried out very carefully, as the nitrogen concentration in the coatings is very sensitive to total pressure changes in the range below $1 \mathrm{~Pa}$. Moreover, an increase of total pressure leads to an undesirable increase in the $\mathrm{O}+\mathrm{N}: \mathrm{Al}$ ratio. The influence of temperature is much less drastic and more controllable, moreover, it has a beneficial influence on this ratio.

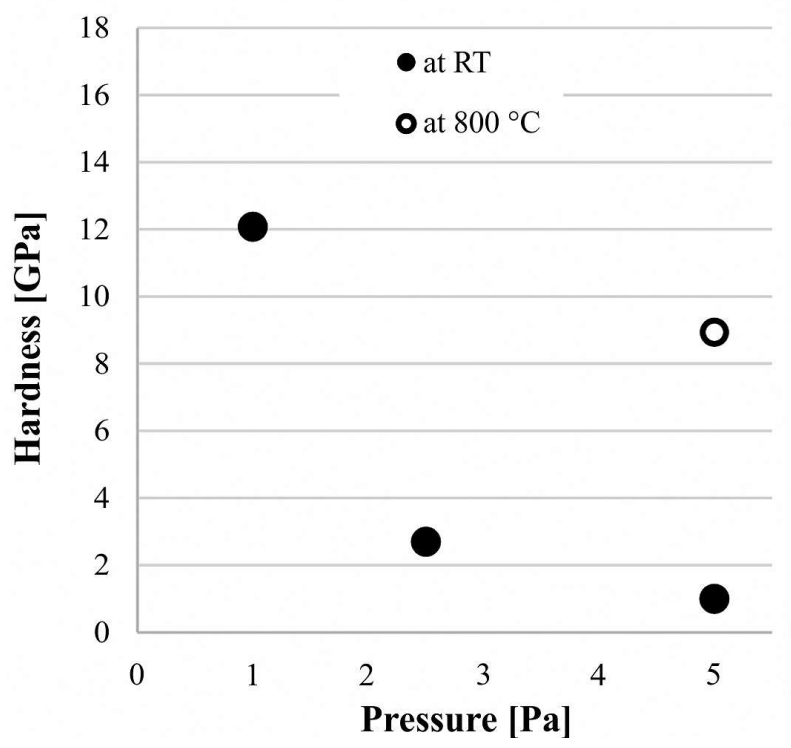

Fig. 9. Hardness of coatings obtained at various deposition pressures.

From the coating quality viewpoint, it is possible to establish an optimum temperature range for which the coatings are characterized by a compact structure and a limited number of droplets. For the conditions applied in the experiments, a substrate temperature between $200{ }^{\circ} \mathrm{C}$ and $400{ }^{\circ} \mathrm{C}$ was found to be the most suitable. An increase of the total pressure had a negative effect on the coating quality. The roughness increased significantly with pressure, moreover, for the highest pressure used, the coatings were not continuous and demonstrated very poor adhesion.

The mechanical properties of the coatings are important indicator of the aluminum oxynitride structure formed as ALON has very high hardness and Young's modulus. None of the coatings obtained in our experiments approached these values. Even for coatings which had similar chemical composition to that of ALON, the mechanical properties were significantly lower [17]. From this point of view, an increase in pressure is not desirable, as a sudden decrease of hardness was observed for the coatings obtained when the total pressure was increased to just above $1 \mathrm{~Pa}$. Increasing the deposition temperature is much more beneficial since it improves the mechanical properties. Especially, 


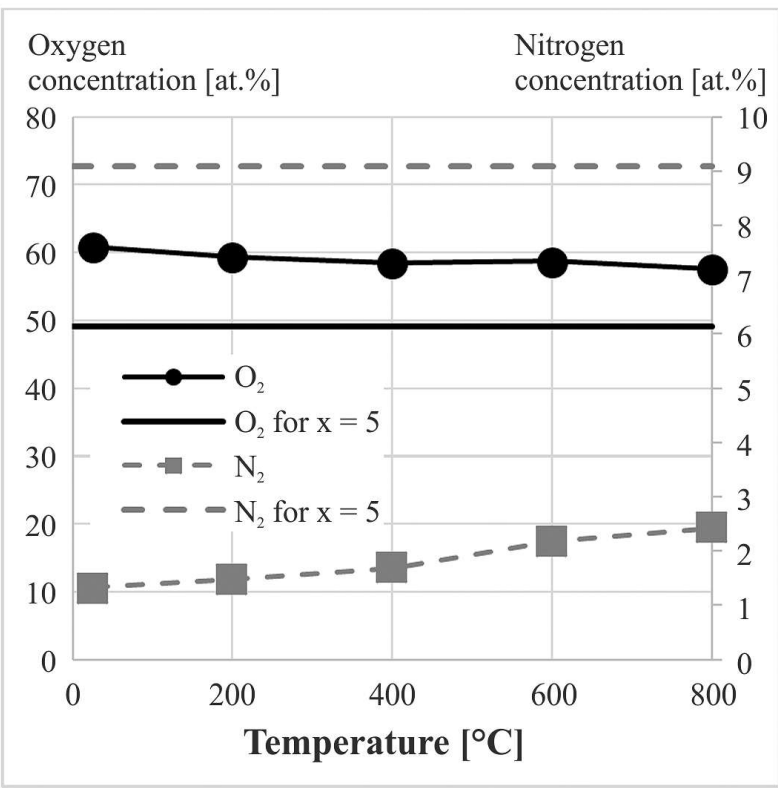

(a)
$\mathrm{N}+\mathrm{O}: \mathrm{Al}$ ratio

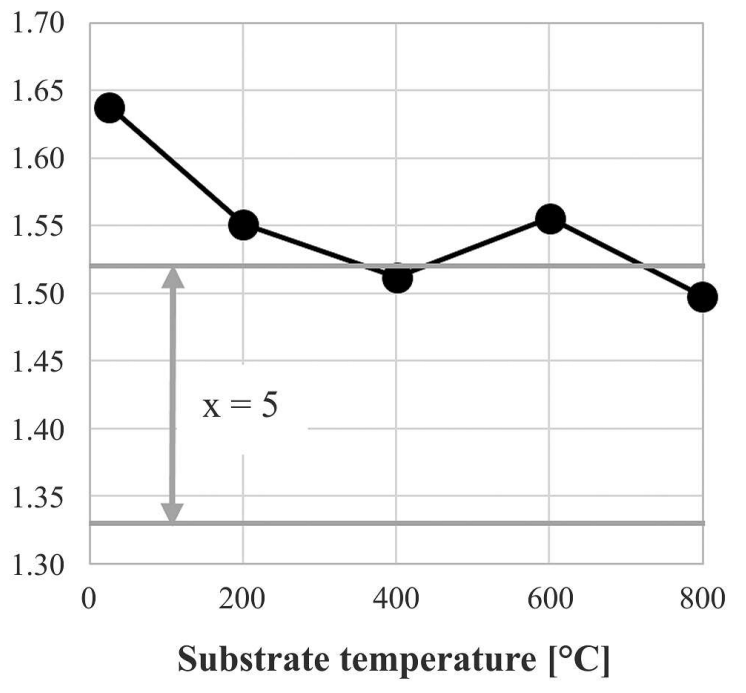

(b)

Fig. 10. Oxygen and nitrogen concentrations (a) and $\mathrm{N}+\mathrm{O}: \mathrm{Al}$ ratio (b) in coatings obtained at different temperatures; EDS and WDS.

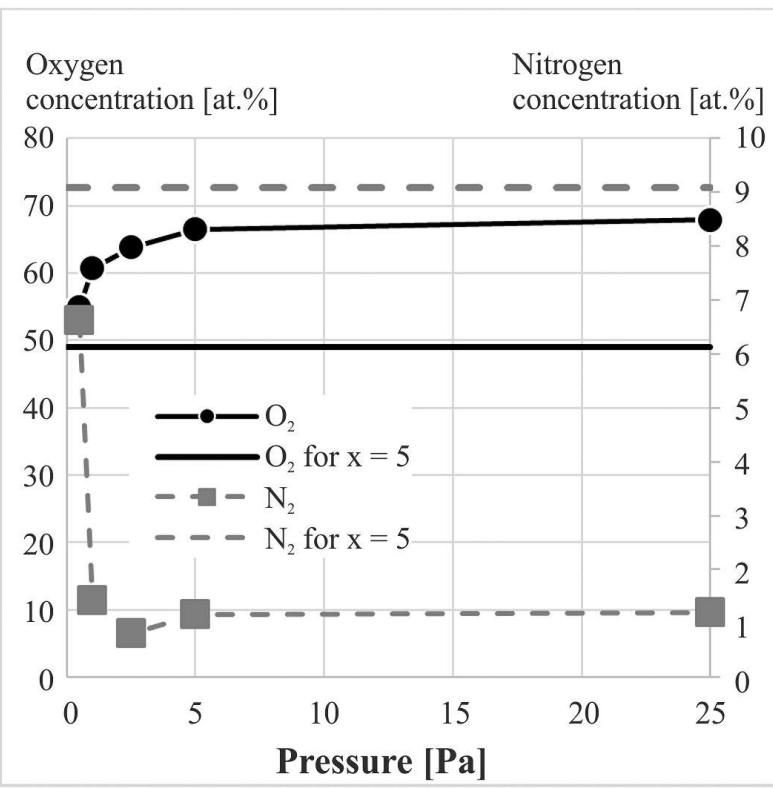

(a)

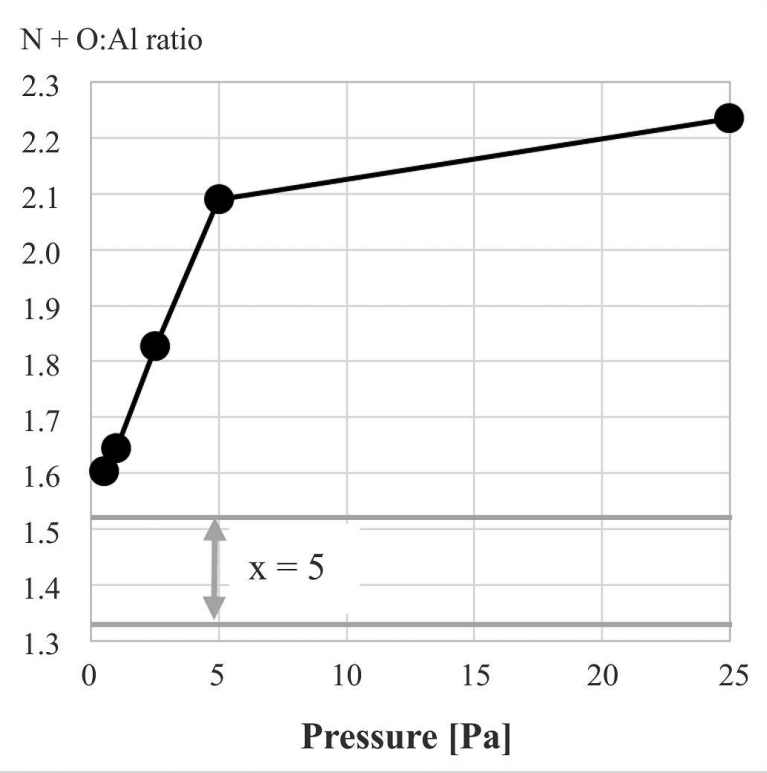

(b)

Fig. 11. Oxygen and nitrogen concentration (a), and $\mathrm{N}+\mathrm{O}: \mathrm{Al}$ ratio (b) in coatings obtained at different pressures; EDS and WDS. 


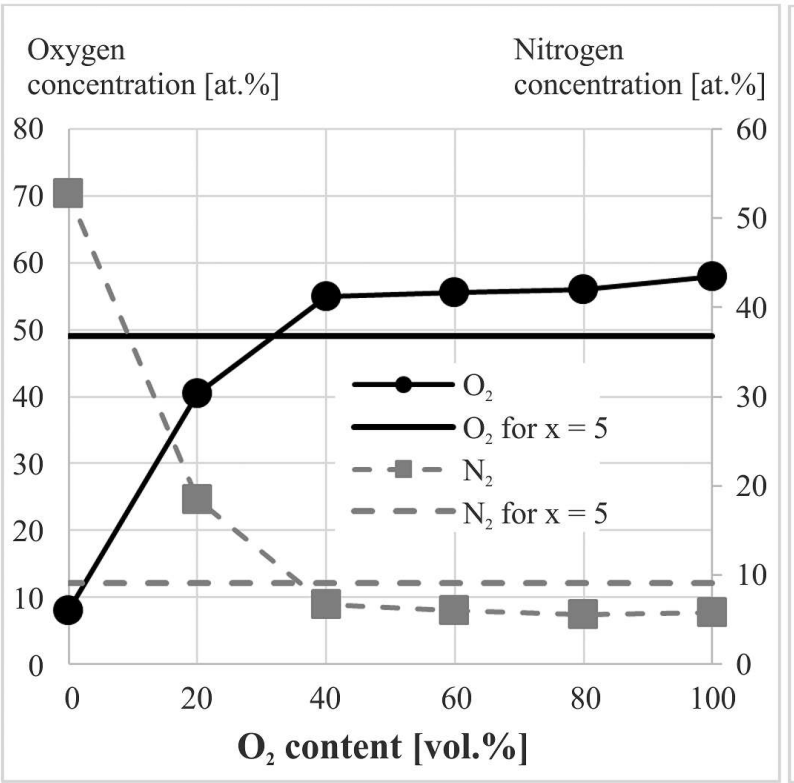

(a)

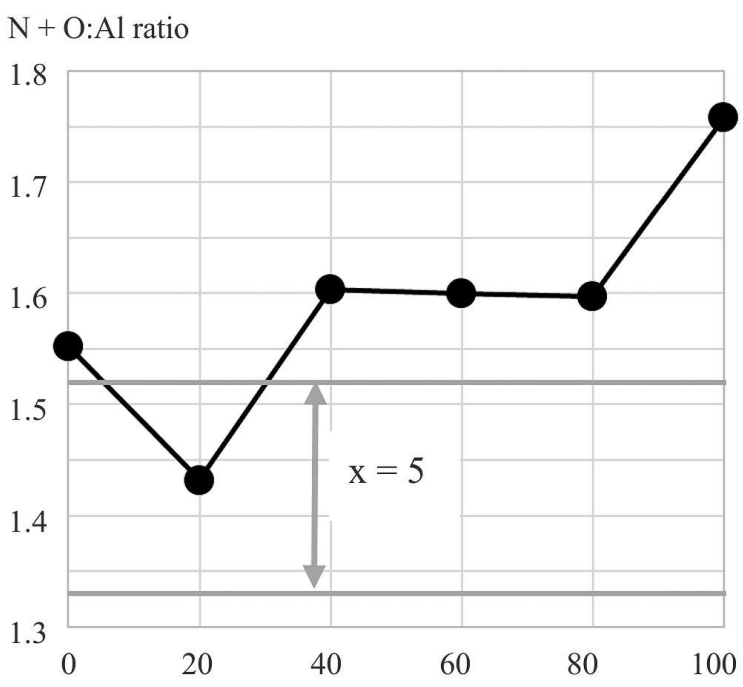

Oxygen content in reactive atmosphere [vol.\%]

(b)

Fig. 12. Oxygen and nitrogen concentration (a), and $\mathrm{N}+\mathrm{O}: \mathrm{Al}$ ratio (b) in coatings obtained at different atmosphere compositions (based on the results presented in the literature [17]); EDS and WDS.

at the highest temperature used, a clear increase of hardness was observed. It was also demonstrated that the temperature increase can compensate to some extent the negative effect of the total pressure.

\section{References}

[1] Zheng J., Forslund B., J. Eur. Ceram. Soc., 15 (1995), 1087.

[2] Li X., Luo J., Zhou Y., J. Eur. Ceram. Soc., 35 (2015), 2027.

[3] Bovard B.G., Thin Solid Films, (1991), 206.

[4] Demiryont H., Thompson L.R., Collins G.J., $J$. Appl. Phys., 59 (1986), 3235.

[5] LiU X.J., Chen F., Zhang F., Zhang H.L., Zhang Z., WANG J., WANG S.W., HuAng Z.R., Int. J. Refract. Met. H., 39 (2013), 38.

[6] Byeon S.S., Wang K., Jung Y.G., Koo B.H., Surf. Coat. Tech., 204 (2010), 3196.

[7] Hartnett T.M., Bernstein S.D., Maguire E.A., Tustison R.W., Infrared Phys. Techn., 39 (1998), 203.

[8] Goldman L.M., Balasubramanian S., NAGENDRA N., SMITH M., ALON®Optical Ceramic Transparencies for Sensor and Armor Applications, in: Alon®Optical Ceramics, http://www.surmet.com/technology/ alon-optical-ceramics/index .php, 2015.

[9] Shan Y., Xu J., Wang G., Ceram. Int., 41 (2015), 3992.
[10] Poyai A., Bunjongrru W., Klunngien N., PornTheerapat S., Mat. Sci. Semicon. Proc., 11 (2008), 319.

[11] Su M., Zhou Y., Wang K., J. Eur. Ceram. Soc., 35 (2015), 1173.

[12] Kim Y.W., PARK H.C., LeE Y.B., J. Eur. Ceram. Soc., 21 (2001), 2383

[13] Zabinski J.S., Hu J.J., Bultman J.E., Pierce N.A., Voevodin A.A., Thin Solid Films, 516 (2008), 6215.

[14] JęDRZEJEWSKI R., BARANOWSKA J., BAŃCZERowsKa P., Inz. Mat. Mater. Eng., 5 (2013), 463.

[15] JęDrzeJEWSKi R., PiWOWARCZYK J., KochMAŃsKi P., BARANOWSKA J., Inz. Mat. Mater. Eng., 6 (2014), 496.

[16] Maghsoudipour A., Moztarzadeh F., SAREMi M., Heinrich J.G., Ceram. Int., 30 (2004), 773.

[17] PIWOWARCZYK J., JĘDRZEJEWSKI R., BARANOWSKA J., Inz. Mat. Mater. Eng., 1 (2016), 14.

[18] LiU M., Man B.Y., Lin X.C., Li X.Y., Chen C.S., Appl. Surf. Sci., 253 (2007), 9291.

[19] Khandelwala R., Singha A.P., Kapoora A., Grigorescub S. Migliettac P., Stankovad N.E., Perronec A., Opt. Laser Technol., 40 (2008), 247.

[20] Lotin A.A., Novodvorsky O.A., Zuev D.A., Khramova O.D., Parshina L.S., LebedeV F.V., Bartha J.W., Wenzel C., Opt. Mater., 35 (2013), 1564. 
[21] LiU M., Wei X.Q., Zhang Z.G., Sun G., Chen C.S., Xue C.S., Zhuang H.Z., Man B.Y., Appl. Surf. Sci., 252 (2006), 4321.

[22] Liua H., Zhang Z., Pana K., MaA J., Yanga L., ZENGA X., Ceram. Int., 41 (2015), 11918.

[23] BALAKRishnaN G., BANDi V.R., RAJESWARI S.M., Balamurugan N., BABU R.V., J.I. Song J.I., Mater. Res. Bull., 48 (2013), 4901.

[24] Zhang W., Wang J., Ji Z., Li H., Lou Y., Yao S., J. Rare. Earth., 28 (2010), 420.

[25] Hasko D., BRUnCKo J., Vacuum, 84 (2010), 166.

[26] Zhang Z.G., Zhou F., Wei X.Q., LiU M., Sun G., Chen C.S., Xue C.S., Zhuang H.Z., Man B.Y., Physica E, 39 (2007), 253.
[27] Farha A.H., Er A.O., Ufuktepe Y., Myneni G., Elsayed-Ali H.E., Surf. Coat. Tech., 206 (2011), 1168.

[28] Wang C., Cheng B.L., Wang S.Y., LU H.B., Y.L. Zhou Y.L., Chen Z.H., Yang G.Z., Thin Solid Films, 485 (2005), 82.
Received 2016-10-16

Accepted 2017-01-22 